\title{
Nuevos aportes a la historia de la eugenesia
}

\section{New contributions to the history of eugenics}

\author{
Héctor A. Palma \\ Escuela de Humanidades/Universidad Nacional de San Martin. \\ Buenos Aires - Buenos Aires - Argentina \\ hpalma@unsam.edu.ar
}

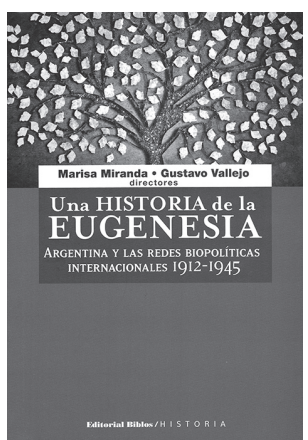

MIRANDA, Marisa; VALLEJO, Gustavo (Dir.). Una historia de la eugenesia: Argentina y las redes biopolíticas internacionales, 19121945. Buenos Aires: Biblos. 2012. 506p.
$\mathrm{E}$ l movimiento eugenésico fue un extendido y complejo programa biopolítico en el cual estuvieron comprometidos importantes sectores de la comunidad científica, política y cultural internacional, cuyo objetivo era el mejoramiento/progreso de la raza, la especie o la población a través de una selección artificial que promoviera la reproducción de determinados individuos o grupos humanos considerados mejores y que redujera la reproducción de otros grupos o individuos considerados inferiores o indeseables. Las principales tecnologías biomédicas y sociales que proponían eran: el Certificado Médico Prenupcial, el control diferencial de la natalidad, la esterilización forzada, el aborto eugenésico, los controles a la inmigración indeseable y las clasificaciones de las personas a través de fichas biotipológicas.

En los últimos años los estudios sobre el movimiento eugenésico en la Argentina y en América Latina se han multiplicado - en buena medida los compiladores de este volumen han sido protagonistas e impulsores de este quehacer a través de la organización de varias reuniones científicas con sendos volúmenes colectivos publicados - con los trabajos de investigadores que han puesto de manifiesto las especificidades nacionales. Sin embargo, aún hay mucho camino por recorrer para establecer las vinculaciones y las redes interestatales, interinstitucionales y las influencias de los pares eugenistas, sobre todo españoles e italianos. En esta línea se inscribe la presente compilación, partiendo de la perspectiva del "análisis de las redes conformadas en torno a la expansión internacional de la eugenesia, especialmente en las que tuvieron a la Argentina como un eslabón destacado". Además de este recorte temático, los artículos toman un periodo clave, el que va desde 1912, cuando se celebró el primer congreso internacional en Londres, hasta 1945, coincidente con el fin de la Segunda Guerra Mundial y con el descrédito de las prácticas que se extendieron, principalmente durante la década del 1930, por casi todo el mundo: la "pérdida de la inocencia" en palabras de Miranda 
y Vallejo (2012). Como quiera que sea, los trabajos compilados refuerzan dos ideas que, si bien no son novedosas para los especialistas, vale la pena recordar: en primer lugar que el movimiento eugenésico excedió ampliamente las fronteras temporales y geográficas del nazismo (aunque éste lo haya llevado al paroxismo) y se extendió a toda América, Europa y parte de Asia; en segundo lugar que fue un complejo entramado de ciencia y política, probablemente el ejemplo más consistente de la biopolítica.

Los artículos - de investigadores, uruguayos, cubanos, peruanos, chilenos, mexicanos, brasileños, españoles y argentinos - recorren un amplio espectro de temas. Con relación a la eugenesia en la Argentina tratan el papel que tuvieron los eugenistas locales en el escenario internacional, en el establecimiento de redes interinstitucionales y su participación en las reuniones científicas que se sucedieron, sobre todo, durante la década del 1930; se explayan en las discusiones sobre la natalidad en línea con los debates europeos de la época, tema clave de los eugenistas convencidos de que la población era escasa y de baja calidad; analizan la influencia de la eugenesia latina en tiempos del fascismo italiano, sobre todo a través del médico Nicola Pende en la Asociación Argentina de Biotipología, Eugenesia y Medicina Social (AABEMS); pero también presentan las vinculaciones de los eugenistas españoles con la AABEMS, la otra gran influencia en Argentina; exponen las repercusiones de la biotipología - una de las más fuertes apuestas de la AABEMS - en la odontología; entregan un análisis del rol reservado a la mujer y la tensión entre mujer-madre y mujer-trabajadora; informan de los vínculos con la psiquiatría y la eugenesia del nacional-catolicismo español; dan a conocer un informe del eugenista norteamericano Harry Laughlin sobre el control eugénico de la inmigración; analizan el rol de la mujer, sus derechos y la cuestión de la maternidad eugénica.

Otros artículos recorren problemas transversales como, por ejemplo, el determinismo biotipológico en los eugenistas españoles, brasileños y argentinos; las vinculaciones entre Renato Kehl (máximo exponente de la eugenesia brasileña) y Víctor Delfino (que intentara, fallidamente, conformar una asociación eugenésica en argentina en 1918, pero que siguió siendo un referente importante en la eugenesia argentina); la apropiación de la eugenesia anglosajona - la otra gran variante, además de la llamada "eugenesia latina" - en Argentina y Chile a través de la ley de esterilización del nazismo.

También hay artículos más específicos, como un estudio sobre la eugenesia peruana y su participación en las redes internacionales; la antropología física y el problema de la raza en el marco de la biotipología en México; y el matrimonio civil y el examen médico prenupcial en la eugenesia chilena.

Cabe destacar un trabajo del ex juez de la Suprema Corte de la República Argentina, Eugenio Zaffaroni, titulado "La mala vida o los prejuicios vestidos de ciencia" que analiza el concepto de "mala vida", un "juicio ético plagado de prejuicios discriminatorios de clase, género y raza" que contribuyó a generar un clima propicio para la recepción de la eugenesia italiana.

Asimismo, hay un artículo de Raquel Álvarez Peláez, una de las precursoras de los estudios sobre la eugenesia, acerca de los inicios de la AABEMS destacando no solo la influencia decisiva del médico italiano Nicola Pende, sino también los vínculos con científicos, intelectuales y políticos españoles. 
Este libro resulta un innegable y valioso aporte a los ya robustos estudios sobre la eugenesia, por un lado, porque se va logrando comprender, con mayor precisión y sutileza, más allá de sus postulados básicos, los ricos matices idiosincráticos que fue adquiriendo el movimiento eugenésico en el proceso de recepción y expansión en los distintos países y regiones; por otro lado, como se dijo al principio, porque va mostrando el frondoso entramado interinstitucional e interestatal que le dio sustento y apoyo concreto para que las tecnologías biomédicas y sociales propuestas pudieran llevarse adelante, con mayor o menor grado de coerción e intervención sobre los cuerpos y las mentes de las personas.

\section{REFERENCIA}

MIRANDA, Marisa; VALLEJO, Gustavo (Dir.).

Una historia de la eugenesia: Argentina y las redes biopolíticas internacionales, 1912-1945. Buenos Aires: Biblos. 2012. 506p. 